Article

\title{
Construction and Quality Analysis of Transgenic Rehmannia glutinosa Containing TMV and CMV Coat Protein
}

\author{
Zhongqiu Teng ${ }^{1,2,3,+}$, Ye Shen ${ }^{1,+}, \operatorname{Jing} \mathrm{Li}^{1}$, Zhongping Lin ${ }^{4}$, Min Chen ${ }^{1}$, Min Wang ${ }^{1}, \mathrm{Man} \mathrm{Li}^{1}$, \\ Hongran Dong ${ }^{1}$ and Luqi Huang ${ }^{1, *}$ \\ 1 State Key Laboratory Breeding Base of Dao-Di Herbs, National Resource Center for Chinese Materia Medica, \\ China Academy of Chinese Medical Sciences, Beijing 100700, China; zhongqiuteng@163.com (Z.T.); \\ shenye70@hotmail.com (Y.S.); justinworking@126.com (J.L.); cm315keke@163.com (M.C.); \\ wangmincacms@sohu.com (M.W.); liman887@163.com (M.L.); dhyopp@126.com (H.D.) \\ 2 State Key Laboratory for Infectious Disease Prevention and Control, National Institute for Communicable \\ Disease Control and Prevention, Chinese Center for Disease Control and Prevention, Beijing 102206, China \\ 3 Collaborative Innovation Center for Diagnosis and Treatment of Infectious Diseases, \\ Hangzhou 310003, China \\ 4 National Key Laboratory of Protein Engineering and Plant Genetic Engineering, College of life science, \\ Peking University, Beijing 100871, China; linzp@pku.edu.cn \\ * Correspondence: huangluqi01@126.com; Tel./Fax: +86-10-6401-4411 \\ + These authors contributed equally to this work.
}

Academic Editor: Derek J. McPhee

Received: 21 July 2016; Accepted: 24 August 2016; Published: 27 August 2016

\begin{abstract}
Plant viruses, especially tobacco mosaic virus (TMV) and cucumber mosaic virus (CMV) are serious threats to Rehmannia glutinosa which is a "top grade" herb in China. In the present study, TMV- and CMV-resistant Rehmannia glutinosa Libosch. plants were constructed by transforming the protein (CP) genes of TMV and CMV into Rehmannia glutinosa via a modified procedure of Agrobacterium tumefaciens-mediated transformation. Integration and expression of TMV CP and CMV CP transgenes in 2 lines, LBA-1 and LBA-2, were confirmed by PCR, Southern blot and RT-PCR. Both LBA-1 and LBA-2 were resistant to infection of homologous TMV and CMV strains. The quality of transgenic Rehmanniae Radix was evaluated based on fingerprint analysis and components quantitative analysis comparing with control root tubes. These results showed that chemical composition of transgenic Rehmanniae Radix were similar to non-transgenic ones, which demonstrated that the medical quality and biosafety of transgenic Rehmanniae Radix were equivalent to non-transgenic material when consumed as traditional Chinese medicinal (TCM).
\end{abstract}

Keywords: virus resistant; Rehmannia glutinosa; transgenic plant; medical quality; biosafety; TMV \& CMV

\section{Introduction}

Rehmannia glutinosa Libosch. (Dihuang), a comprehensive traditional Chinese medicinal (TCM) herb, was considered as a "top grade" herb in China [1]. Raw and processed Rehmanniae Radix are reported to possess many kinds of pharmacological activity, such as clearing away heat [2], promoting salivation [3], nourishing "yin" [4], promoting the production of body fluids [5] and benefitting the marrow [6], etc. Supply of the medical material is becoming increasingly scarce due to production reductions and increasing quality requirements. Germplasm degradation caused by tobacco mosaic virus (TMV) and cucumber mosaic virus (CMV) infection is one of important factors which has a huge impact on the production of Rehmannia glutinosa $[7,8]$. A coat protein-mediated resistance (CP-MR) strategy against plant viruses has been established and applied in the development of transgenic 
plants [9]. Powell-Abel et al. reported that transgenic tobacco plants with the coat protein genes of TMV showed delayed appearance of severe TMV symptoms [10]. After decades of development, virus-resistant transgenic plants producing certain CPs of different viruses, including TMV [11], CMV [12], soybean dwarf virus (SbDV) [13], alstroemeria mosaic virus (AIMV) [14], potato virus $X$ (PVX) [15], potato virus Y (PVY) [16] and so on, were established. Hence, transgenic CP-MR strategy offers a powerful tool to overcome plant virus diseases. The development of Rehmannia glutinosa cultivars resistant to TMV and CMV is necessary because of the serious damage to its production.

In the present work, we describe a procedure for transformation of Rehmannia glutinosa Libosch. (cultivar "Wen 85-5"). We transformed a construct containing the CP genes of TMV and CMV into wild Rehmannia glutinosa to acquire TMV and CMV resistant Rehmannia glutinosa plants. The expression of transgenes in transgenic progenies was confirmed. TMV and CMV resistance were also investigated. More important, the trial here involved construction of a kind of transgenic traditional Chinese medicine which is frequently used in the clinic. The medicinal quality and biosafety of transgenic Rehmanniae Radix was assessed via comparison of UPLC-MS fingerprints, the content of polysaccharide and active components with the wild counterpart.

\section{Results}

\subsection{Establishment and Optimization of Transformation System}

The morphogenetic ability of different varieties of Rehmannia glutinosa is different due to the distinct genotypes. Experimental conditions such as hormone type and concentration, illumination time and environmental temperature, etc. have a significant effect on the time of callus induction and bud differentiation. In the present study, an L16 (45) orthogonal array was used to optimize of transformation conditions. All five variables (pre-culture time, co-culture time, infection time, infection concentration and phytohormones) were varied at four levels (Supplementary Table S1). The results (Supplementary Tables S2-S4) indicated that pre-culture time, co-culture or the five factors of time, time of infection, bacteria concentration and hormone had no significant impact on sprouting rate. Pre-culture time concentration of bacterium and co-culture time has remarkable influence on the differentiation rate of positive plants on account of the higher F value (Supplementary Table S4). The optimum conditions for Rehmannia glutinosa leaf genetic transformation were as follows: Rehmannia glutinosa leaves free of pre-culture were inoculated with Agrobacterium $\left(\mathrm{OD}_{600}=0.4\right)$ for $8 \mathrm{~min}$; after $36 \mathrm{~h}$ of co-culture, transfer the leaves to differentiation medium (MS + 6-BA $2 \mathrm{mg} / \mathrm{L}+\mathrm{NAA} 0.5 \mathrm{mg} / \mathrm{L}+$ cefotaxime $100 \mathrm{mg} / \mathrm{L}$ ) and refresh the culture medium every 20 days until the differentiation of adventitious buds; and then transfer the adventitious bud to the rooting medium.

\subsection{Construction of Transgenic Plants}

Binary vector constructions were transferred into the disarmed Agrobacterium strain LBA4404 and subsequently into Rehmannia glutinosa. Three PPT resistant plants (LBA-1, LBA-2 and LBA-3) were finally obtained from 120 of leaf-disc after infection of Agrobacterium containing pCAM-TM35SC plasmid. The three independent transgenic lines were identified based on PCR, RT-PCR and also by genomic Southern blot analysis. PCR showed that the three transgenic Rehmannia glutinosa lines contained TMV-CP and CMV-CP genes (Figure 1). RT-PCR suggested that LBA-1 and LBA-2 contained markedly enhanced amounts of TMV-CP and CMV-CP mRNA. However, LBA-3 was free of CMV-CP mRNA even though TMV-CP gene can be expressed in the transgenic line (Figure 2). We also got similar results in the genomic Southern blot analysis. Both TMV-CP gene and CMV-CP gene were confirmed to be integrated into the chromosomes of LBA-1 and LBA-2 by Southern blotting. The Southern blotting analysis of LBA-3 indicated that only TMV-CP was integrated into chromosomes of the line, but CMV-CP was not (Figure 3). Therefore, transgenic lines LBA-1 and LBA-2 were used for further studies. 


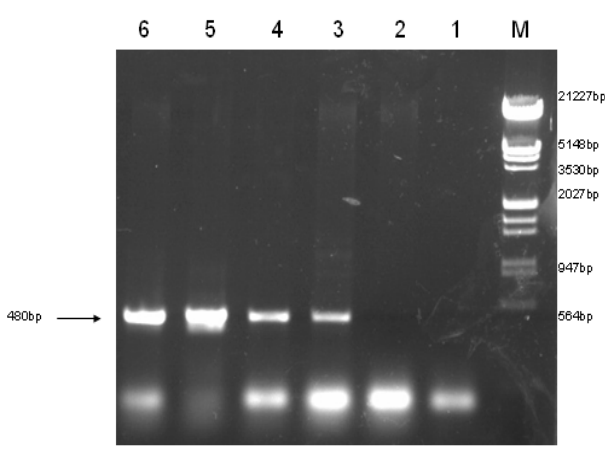

(a) TMV CP

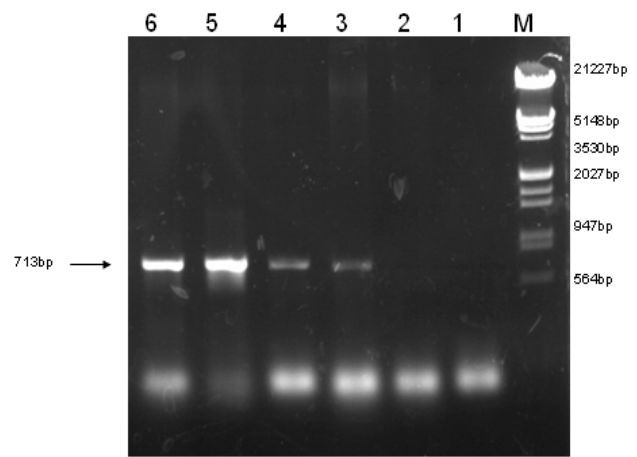

(b) CMV CP

Figure 1. The TMV CP gene (a) and CMV CP gene (b) fragments amplified by PCR. DNA fragments with expected sizes (TMV CP gene: 480 bp; CMV CP gene: 713 bp) were observed in LBA-1, LBA-2 and LBA-3; no PCR product appeared from wild type (85-5). M: Marker; 1 : Control $\left(\mathrm{ddH}_{2} \mathrm{O}\right) ; 2$ : PCR product of 85-5; 3: PCR product of LBA-1; 4: PCR product of LBA-2; 5: PCR product of LBA-3; 6: PCR product of pCAM-TM35SCM.

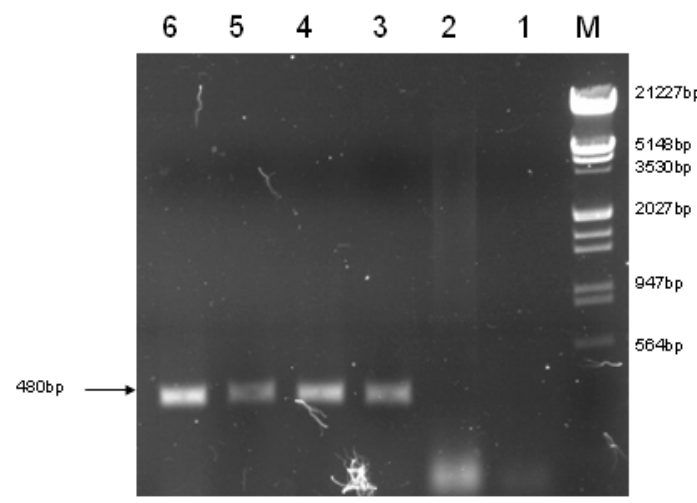

(a) TMV CP

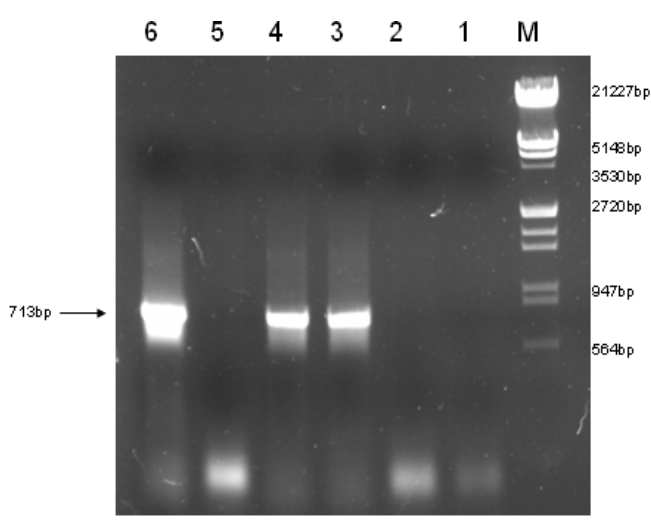

(b) CMV CP

Figure 2. RT-PCR analysis of the TMV CP gene (a) and CMV CP gene (b). The expected size of the amplified portion of the TMV CP gene transcript were observed in LBA-1, LBA-2 and LBA-3; a fragment of ca. $713 \mathrm{bp}$, corresponding to the amplified portion of the CMV CP gene transcript were observed in LBA-1 and LBA-2, but absent in LBA-3. M: Marker; 1 : Control $\left(\mathrm{ddH}_{2} \mathrm{O}\right)$; 2: PCR product of 85-5; 3: PCR product of LBA-1; 4: PCR product of LBA-2; 5: PCR product of LBA-3; 6: PCR product of PCAM-TM35SCM.

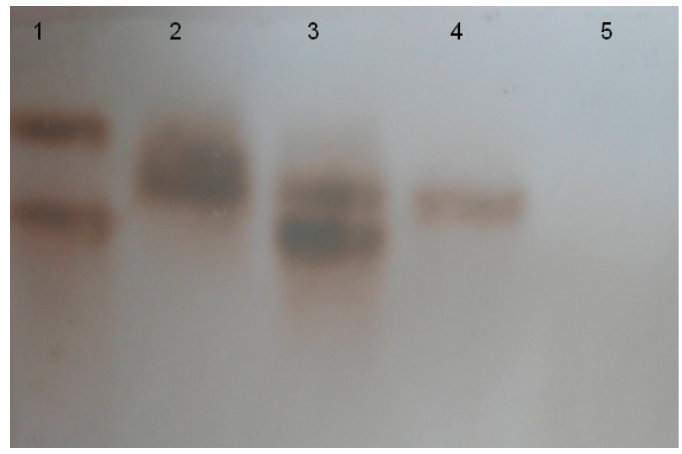

(a) TMV CP

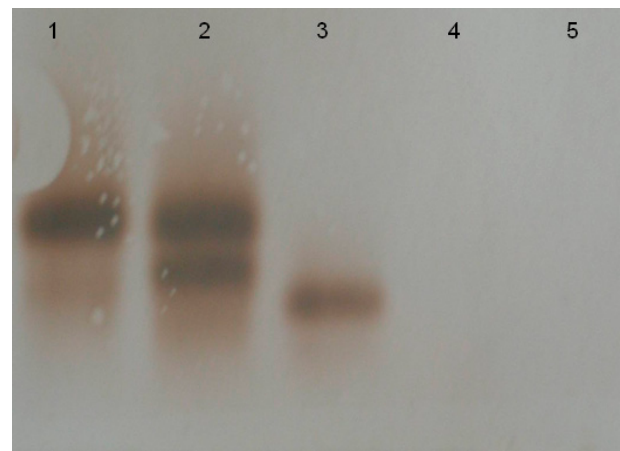

(b) CMV CP

Figure 3. Southern analysis of transgenic plants. The Southern blot analysis demonstrated the presence of TMV CP gene (a) and CMV CP gene (b) copy in the genome of LBA-1 and LBA-2. 1: positive control; 2: LBA-1; 3: LBA-2; 4: LBA-3; 5: 85-5. 


\subsection{Virus Resistance of Transgenic Lines}

To assess virus resistance of transgenic lines expressing the TMV-CP and CMV-CP (LBA-1 and LBA-2), and wild type Rehmannia glutinosa plants were infected by biotrophic TMV and CMV.

The illness conditions of test plants were linked to the virus inoculation concentration. High virus concentration causes serious Rehmannia glutinosa illness, and even death. On the contrary, the illness maybe too light to evaluate illness conditions when the virus concentration is too low, so the best inoculation concentration of TMV and CMV was investigated before the virus resistance test (Supplementary Table S5). Finally, $0.1 \mu \mathrm{g} / \mathrm{mL}$ of virus was selected as the optimum concentration. Figure 4 shows the incidence of Rehmannia glutinosa infected by TMV. The incidence rate of LBA-1 and LBA-2 was significantly less than in the wild line within 8 days after inoculation. LBA-2 maintained a low incidence for more than 10 days. However, all the LBA-1 and wild line Rehmannia glutinosa plants suffered TMV disease after 8 days. The disease index test was also determined in order to investigate the TMV resistance of Rehmannia glutinosa according to grade and tobacco disease investigation method of (Industry criteria of the tobacco industry of China, YC/T 39-1996). The disease indexes of LBA-1, LBA-2 and wild type Rehmannia glutinosa were 42.9, 37 and 15, respectively. LBA-2 was thus classified as a resistant plant $(5<$ disease index $\leq 20)$, which showed excellent resistance to TMV virus. LBA-1 was a medium resistance plant $(20<$ disease index $\leq 40)$, which TMV resistance was slightly higher than that of the wild type (susceptible plant, $40<$ disease index $\leq 60$ ). The same experiment was performed on CMV resistance of Rehmannia glutinosa. LBA-1 showed CMV disease symptoms soon after CMV inoculation, but showed a significantly lower incidence compared with wild type Rehmannia glutinosa during the observation time, as shown in Figure 5. The CMV disease incidence of LBA-2 was lower than that of LBA-1 and the wild lines. In addition, LBA-2 was a resistant plant (disease index $=10$ ), and LBA-1 was a medium resistance plant (disease index $=30$ ). We also compared the symptoms of Rehmannia glutinosa leaves 10 days after inoculation with the virus (Figures 6 and 7).

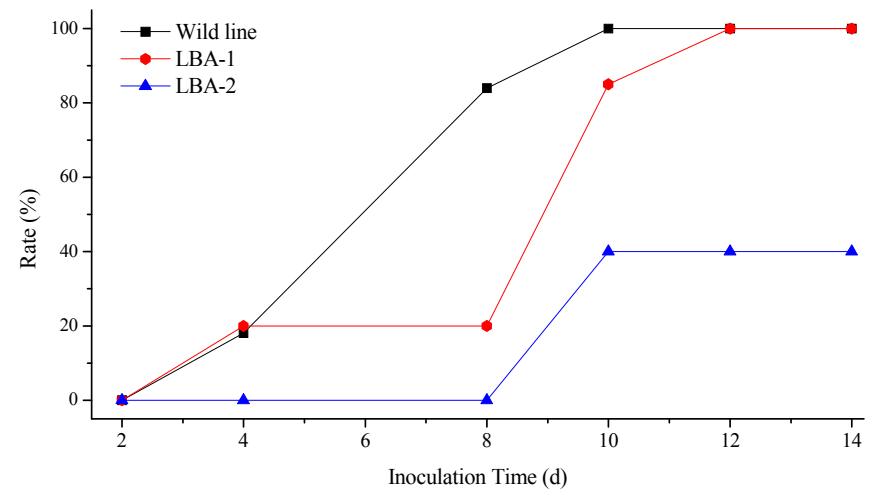

Figure 4. Incidence of Rehmannia glutinosa after inoculation of TMV.

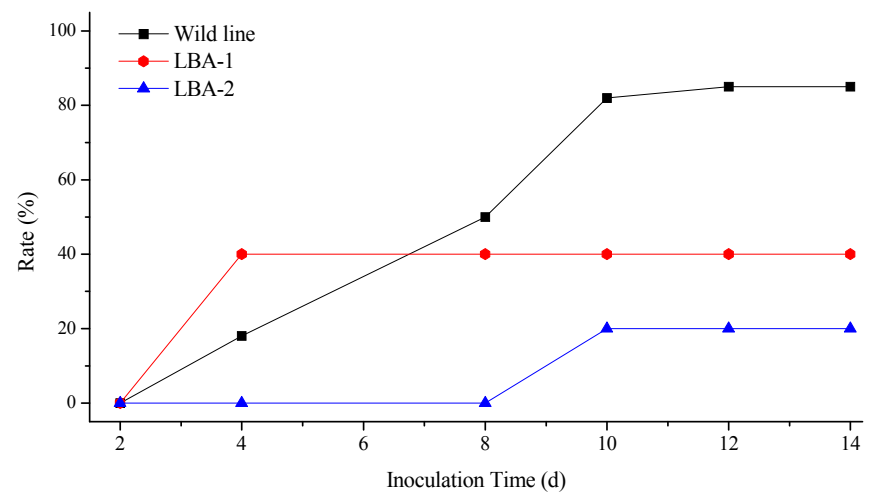

Figure 5. Incidence of Rehmannia glutinosa after inoculation of CMV. 


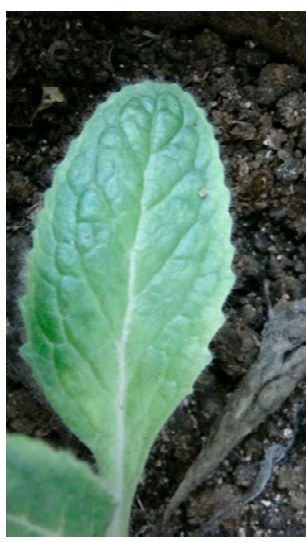

(a)

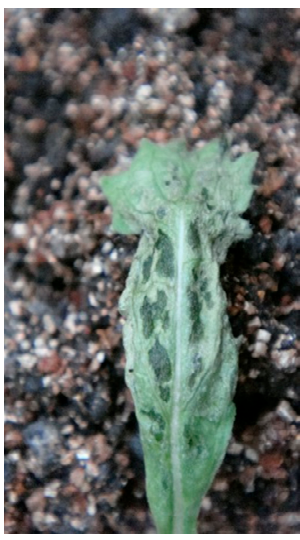

(b)

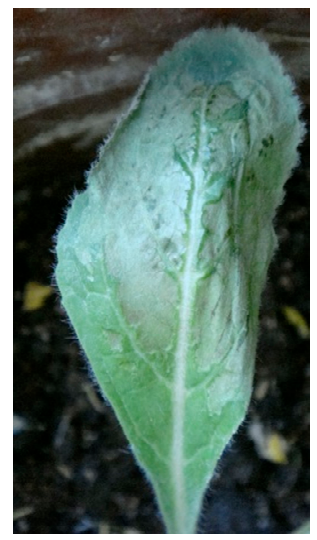

(c)

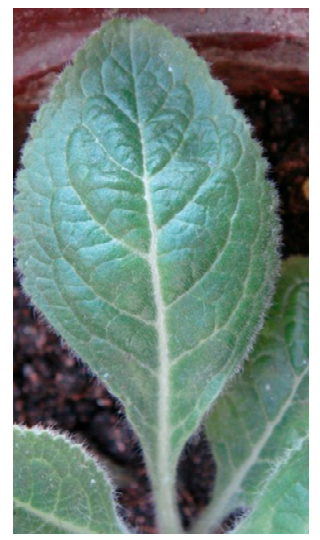

(d)

Figure 6. Symptoms of Rehmannia glutinosa leaves 10 days after inoculation of the TMV. (a) control; (b) wild line; (c) LBA-1; (d) LBA-2.

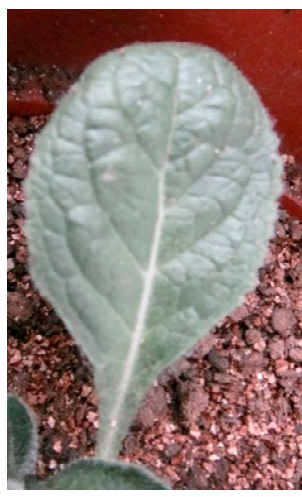

(a)

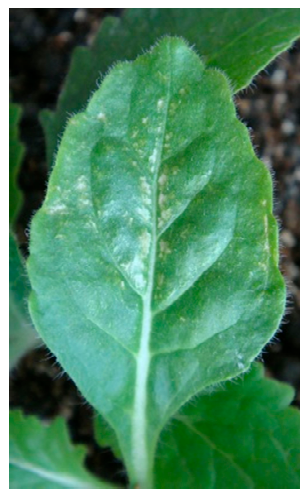

(b)

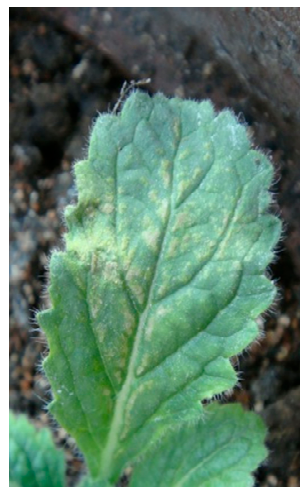

(c)

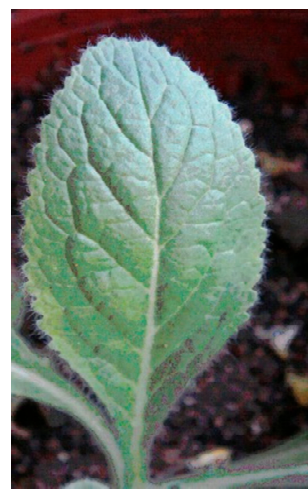

(d)

Figure 7. Symptoms of Rehmannia glutinosa leaves 10 days after inoculation with CMV. (a) control; (b) wild line; (c) LBA-1; (d) LBA-2.

The virus infection symptoms of LBA1 were less than those of the wild lines. Most inoculated leaves of LBA-2 almost showed no symptoms. In summary, both LBA-1 and LBA-2 were TMV and CMV resistant Rehmannia glutinosa lines, and LBA-2 showed better virus resistance as measured by disease index and disease incidence tests than LBA-1.

\subsection{Quality Evaluation of Transgenic Rehmannia glutinosa}

Using the UPLC-MS fingerprint of wild Rehmanniae Radix as the standard pattern against which to compare other preparations, two different genotypes of Rehmanniae Radix samples were comparatively analyzed (Supplementary Figure S4). The similarities between the chromatograms of the two groups of samples $(n=10)$ compared with the reference fingerprint were close to 1 , as shown in Table 1 and Supplementary Figure S4c. The results indicated that the chromatographic patterns of transgenic samples were consistent with the wild type Rehmanniae Radix.

Table 1. The similarities of chromatograms of LBA-1 and LBA-2 to wild line.

\begin{tabular}{cccccccccccc}
\hline Lines & $\mathbf{1}$ & $\mathbf{2}$ & $\mathbf{3}$ & $\mathbf{4}$ & $\mathbf{5}$ & $\mathbf{6}$ & $\mathbf{7}$ & $\mathbf{8}$ & $\mathbf{9}$ & $\mathbf{1 0}$ & Mean \\
\hline LBA-1 & 0.899 & 0.941 & 0.893 & 0.916 & 0.918 & 0.989 & 0.99 & 0.987 & 0.991 & 0.982 & 0.951 \\
LBA-2 & 0.940 & 0.953 & 0.899 & 0.910 & 0.902 & 0.937 & 0.926 & 0.928 & 0.991 & 0.987 & 0.937 \\
\hline
\end{tabular}


Catalpol, aucubin, leonuride, acteoside, echinacoside and polysaccharides are considered the bio-active components of Rehmanniae Radix. The contents of the compounds and polysaccharides in transgenic Rehmanniae Radix compared with the wild type are shown in Table 2. The contents of the five compounds and total polysaccharides in transgenic type were closed to that of wild types. Moreover, the contents of analytes in every group of Rehmanniae Radix showed no statistically differences. The results indicated that the medical quality of transgenic Rehmanniae Radix maybe equivalent to non-transgenic material when consumed as a traditional Chinese medicine.

Table 2. Contents of main compounds and polysaccharides in different gene type Rehmanniae Radix.

\begin{tabular}{ccccccc}
\hline \multirow{2}{*}{ Lines } & \multirow{2}{*}{$\begin{array}{c}\text { Polysaccharides } \\
(\mathbf{m g} / \mathbf{g})\end{array}$} & Aucubin & Catalpol & Ajugol & Acteoside & Echinacoside \\
\cline { 3 - 7 } & & $17.80 \pm 2.88$ & $683.57 \pm 120.12$ & $189.21 \pm 22.49$ & $1.25 \pm 0.45$ & $5.71 \pm 1.34$ \\
Wild lines & $33.66 \pm 1.82$ & 17.45 & \multicolumn{1}{c}{ Main Compounds $(\mathbf{m g} / \mathbf{g})$} \\
LBA-1 & $33.47 \pm 1.61$ & $17.84 \pm 3.55$ & $687.20 \pm 112.35$ & $186.93 \pm 18.11$ & $1.25 \pm 0.46$ & $5.74 \pm 2.34$ \\
LBA-2 & $33.22 \pm 1.69$ & $17.76 \pm 3.75$ & $682.67 \pm 132.77$ & $187.59 \pm 22.12$ & $1.26 \pm 0.28$ & $5.73 \pm 1.60$ \\
\hline
\end{tabular}

\section{Discussion}

TMV and CMV infections reduce agricultural productivity worldwide [17]. Combined infection of these two kinds of plant virus causes more severe symptoms, even yellow withered crops [18,19]. Breeding virus-resistant plants via gene modification is considered an effective way to control virus infection [20-22]. Cultivation of Rehmannia glutinosa-a kind of the bulk Chinese herbal medicine-suffers from infection by TMV and CMV in producing areas. Coat protein mediated protection (CPMP) has been established in transgenic plants against many kinds of plant virus [23-25]. The same strategy was used here to develop virus-resistant Rehmannia glutinosa transformed with the CMV-CP and TMV-CP genes. Two transgenic lines (LBA-1 and LBA-2) were confirmed to express both exogenous virus CP genes. In order to test the antiviral capacity of Rehmannia glutinosa lines, transgenic Rehmannia glutinosa and wild line were inoculated with TMV and CMV. Both LBA-1 and LBA-2 were TMV and CMV resistant Rehmannia glutinosa lines. However, the antiviral capacities of the two transgenic lines were different, as LBA-2 showed better virus resistance as measured by disease index and disease incidence tests than LBA-1.

Transgenic technology can improve certain characteristics of the medicinal plants, such as antiviral resistance, improved resistance to diseases in general and enhanced contents of effective compounds. As a commonly used Chinese herbal medicine, Rehmannia glutinosa is different from some other medicinal plants which often used as raw materials for extracting effective components. For example, Artemisia carvifolia is used for the extraction of antimalarial constituents [26]. Rehmannia glutinosa has always been applied in Chinese medicine as a decoction which is taken orally after decocting in water, or directly used in proprietary Chinese medicine preparations. Therefore, we need to pay attention to the quality and safety of transgenic Rehmannia glutinosa. In the present study, contents of several major bio-active compounds (three iridoid glycosides and two phenethyl alcohol glycosides) and total polysaccharides (considered as the main constituents responsible for the tonic effect) in transgenic Rehmannia glutinosa were compared with their wild counterpart. Furthermore, fingerprint technology which has been widely used in quality control of TMC $[27,28]$ was applied in a comparative study between transgenic and wild Rehmannia glutinosa. The tubers of transgenic Rehmannia glutinosa showed similar chemical compositions as their wild counterpart. Chemical composition is the material basis of Chinese herbal medicine efficacy. The similar chemical compositions of different Rehmannia glutinosa suggest that exogenous gene introduction had no effect on the medicinal quality of the medical plant. Consumers and regulatory authorities pay more attention to the safety of transgenic plants. Substantial equivalence is considered as the principal criterion for assessing the safety of novel foodstuffs, the principle being that, composition of the novel (i.e., transgenic) foodstuff should not differ in a meaningful way from a traditional (i.e., unmodified) variety(s) $[29,30]$, so the similar chemical composition of transgenic and wild Rehmannia glutinosa also provides preliminary evidence of the 
safety of the two transgenic Rehmannia glutinosa lines. Agronomic traits and further safety evaluation shall be the focus in our further studies.

\section{Materials and Methods}

\subsection{Reagents and Plant Material}

Agar powder, MS medium, kanamycin, rifampicin, glufosinate ammonium (PPT), CTAB, Taq DNA polymerase, TransStart FastDNA polymerase, agarose biochemical reagent were purchased from Sigma (St. Louis, MO, USA). All primers were provided by Shanghai SANGON Biological Engineering Co., Ltd. (Shanghai, China) pCAMBIA3301 was digested with restriction endonuclease purchased from Shanghai Solarbio Bioscience \& Technology Co., Ltd. (Shanghai, China).

Methanol and acetonitrile (HPLC Grade) were purchased from Fisher Scientific (Fair Lawn, NJ, USA). Distilled water, prepared by a Milli-Q water purification system (Millipore Corp., Bedford, MA, USA) was used throughout the study. Catalpol, aucubin, leonuride, acteoside and echinacoside were purchased from Beijing Qian He Biotechnology Co., Ltd. (Beijing, China).

Rehmannia glutinosa plants were obtained from Wuzhi County, Henan Province, China and authenticated by Professor Hongyan Liu (Henan Academy of Agriculture Sciences). The plants were maintained at $23-25{ }^{\circ} \mathrm{C}$ under $100 \mathrm{mmol} / \mathrm{m}^{2} / \mathrm{s}$ photosynthetic photon flux density with a day length of $16 \mathrm{~h}$.

\subsection{Construction of the Plant Expression Plasmid}

The disarmed A. tumefaciens LBA4404 carrying the binary vector PCAM-TM35SCM was used to transform Rehmannia glutinosa plants. The plasmid was constructed as follows: the TMV-CP gene was amplified by PCR from the corresponding CDNA clone of TMV strain (Rehmannia mosaic virus, a member of the TMV), using primers with each appropriate restriction enzyme recognition site, and inserted into pCAMBIA3301 vector to form the pCAMBIA-TM vector. Then HindIII-CaMV35S-GUS-Tnos-BstI amplified using pBI121 vector as a template was inserted (pCAM-TM35S). The binary vector PCAM-TM35SCM was finally constructed by inserting CMV-CP gene which were cloned from the CMV Shandong isolate (SD-CMV) belonging to subgroup 1 with SmaI and SacI restriction sites into pCAM-TM35S.

\subsection{Leaf Disc Transformation of Rehmannia glutinosa}

Transgenic plants of Rehmannia glutinosa expressing the TMV-CP and CMV-CP genes were leaf-disc transformed with the Agrobacterium tumefaciens strain LB4404 containing the TMV-CP and CMV-CP genes. Infected explants were grown on MS medium with a feeder layer. After 2 days of culture, the explants were transferred onto callus medium prepared with $0.5 \mathrm{mg} / \mathrm{mL}$ claforan for the elimination of Agrobacterium cells. Medium must be replaced by fresh medium every 20 days until adventitious buds are differentiated. Thereafter, transgenic plants were selected on fresh MS plates that contained $0.5 \mathrm{mg} / \mathrm{mL}$ claforan and glufosinate (PPT). Regenerated shoots with PPT resistance were induced to root on one-half MS-medium containing $0.7 \%$ Phyto-agar.

\subsection{PCR of Transgenic Plants}

Genomic DNA of Rehmannia glutinosa was extracted from four-week-old plant leaves using a modified hexadecetyltrimethyl ammonium bromide (CTAB) method. About $0.2 \mathrm{~g}$ of fresh leaf tissue frozen in liquid nitrogen was ground in $1.5 \mathrm{~mL}$ Eppendorf tubes with a frozen mill. Then, $0.5 \mathrm{~mL}$ of $2 \%$ CTAB buffer was added into the tubes and incubated at $65{ }^{\circ} \mathrm{C}$ for $60 \mathrm{~min}$. After incubation, $0.6 \mathrm{~mL}$ of chloroform-isoamyl alcohol $(24: 1, v / v)$ was added into the samples and mixed twice. The tubes were centrifuged for $10 \mathrm{~min}$ at $13,000 \mathrm{rpm}$ under $4{ }^{\circ} \mathrm{C}$. The supernatant was removed and $0.5 \mathrm{~mL}$ of isopropanol added and left at $-20^{\circ} \mathrm{C}$ for at least 3 days. The supernatant $(0.5 \mathrm{~mL})$ was transferred into a new tube and the DNA precipitated in $0.5 \mathrm{~mL}$ 
of 2-propanol at $-20^{\circ} \mathrm{C}$ for $2 \mathrm{~h}$. The supernatant was removed after $10 \mathrm{~min}$ centrifugation at 13,000 rpm under $4{ }^{\circ} \mathrm{C}$. The DNA was then washed with $70 \%$ ethanol and dissolved in TE buffer. The selected transformants were analyzed by PCR using TMV-CP (F-T1: 5'-ATGTCTTATACAATT GCAACTCCATCCCA-3' and F-T2: 3'-TCAAGTTGCGGGACCAGAAGTCCAG-5') and CMV-CP (R-C1: 5'-ATGTCTTATACAATTGCAACTCCATCCCA-3' and R-C2: 3'-TCAAGTTGCGG GACCAGAAGTCCAG-5') gene-specific primers.

\subsection{RT-PCR of Transgenic Plants}

The total leaf RNA ( $3 \mu \mathrm{g}$ ) was isolated from four-week-old plant leaves with TRIZOL reagent (Invitrogen Corp., Carlsbad, CA, USA) as described previously [31]. First-strain cDNA was synthesized using M-MLV Reverse Transcriptase (Promega Corp., Madison, WI, USA). For RT-PCR analysis, $1 \mu \mathrm{L}$ of the first strand cDNA reaction products and high fidelity Ex-Taq polymerase (Takara Bio Inc., Kyoto, Japan) were used in a total volume of $30 \mu \mathrm{L}$. The reaction consisted of 27 cycles of $30 \mathrm{~s}$ at $95{ }^{\circ} \mathrm{C}, 40 \mathrm{~s}$ at $55^{\circ} \mathrm{C}$, and $1 \mathrm{~min}$ at $72{ }^{\circ} \mathrm{C}$.

\subsection{Southern Blotting}

Southern-blotting analysis was carried out for confirming TMV-CP and CMV-CP genes were inserted into the chromosome of the transgenic strains. To generate templates for cDNA probes, the full-length TMV-CP and CMV-CP genes were cut out of plasmid pCAM-TM35SCM, respectively. cDNA Probes were labelled with digoxin by random primer method according to DIG High Prime DNA Labeling and Detection Starter Kit 1 (Roche Crop., Mannheim, Germany). Genomic DNA (10 $\mu \mathrm{g})$ isolated from transgenic and wild-type Rehmannia glutinosa were digested with EcoRI, fractionated in a $0.7 \%$ agarose gel, and transferred to a nylon membrane. Hybridization and detection were performed according to the kit protocol.

\section{7. $T M V$ and $C M V$ Infections}

Before TMV and CMV infection, transgenic and wild-lines of Rehmannia glutinosa were transplanted into the greenhouse $\left(20-28{ }^{\circ} \mathrm{C}\right.$, natural light) after seedling adaptation. Healthy plants were selected for the virus infection tests. A layer of quartz sand was evenly sprinkled on the first and second leaves at 2-3 leaf stage of the transplanted Rehmannia glutinosa seedlings. Then the leaves were rubbed gently using a brush with homologous TMV strain seeding solution prepared as described [32] and rinsed with distilled water. Control plants were inoculated using phosphate buffer solution without TMV. CMV (SD-CMV) infection operation followed the same procedure. The disease rate and disease index of the virus-invaded Rehmannia glutinosa was assessed according to grade and the investigation method of tobacco disease (Industry criteria of the tobacco industry of China, YC/T 39-1996).

\subsection{Chromatographic Fingerprint Analysis of Rehmanniae Radix}

The test samples were collected from the planting greenhouse and were dried at room temperature. Ten $\mathrm{mg}$ of each sample were weighed and extracted with ultrasound-assistance $(32,000 \mathrm{~Hz})$ for $5 \mathrm{~min}$ in $10 \mathrm{~mL}$ methanol at $25^{\circ} \mathrm{C}$. Methanol was used to make the final volume up to $10 \mathrm{~mL}$. The samples were filtered through a $0.22 \mu \mathrm{m}$ membrane before injection into the UPLC system. Separations were carried out with a Waters Acquity HSS T3 column $(100 \times 2.1 \mathrm{~mm}, 1.8 \mu \mathrm{m}$, Waters Corp., Milford, MA, USA). The mobile phase consisted of (A): water containing $0.1 \%$ formic acid; and (B): acetonitrile containing $0.1 \%$ formic acid; a gradient programmer was used according to the following profile: isocratic $2 \% \mathrm{~B}(0-1 \mathrm{~min})$, linear gradient from $2 \%$ to $5 \% \mathrm{~B}(1-2 \mathrm{~min}), 5 \%$ to $12 \% \mathrm{~B}(2-5 \mathrm{~min}), 12 \%$ to $20 \%$ B (5-10 $\mathrm{min}), 20 \%$ to $30 \% \mathrm{~B}(10-12 \mathrm{~min}), 30 \%$ to $51.5 \% \mathrm{~B}(12-13.5 \mathrm{~min}), 50 \%$ to $100 \% \mathrm{~B}(13.5-16 \mathrm{~min})$, isocratic $100 \%$ B for $2 \mathrm{~min}$. The flow rate was $0.5 \mathrm{~mL} / \mathrm{min}$ and column temperature was maintained at $30^{\circ} \mathrm{C}$. The injection volume was $1 \mu \mathrm{L}$. Mass spectrometry was performed with an Electron Spray Ionization (ESI) source operating in negative ion mode. The source temperature was set at $100{ }^{\circ} \mathrm{C}$ and 
the desolvation temperature was set at $450{ }^{\circ} \mathrm{C}$ with desolvation gas flow of $900 \mathrm{~L} / \mathrm{h}$. The capillary voltage and cone voltage were set to $3 \mathrm{kV}$ and $40 \mathrm{~V}$, respectively. A mass range scanned was set from 50 to $1500 \mathrm{Da}$ and Scan Time was $0.2 \mathrm{~s}^{-1}$.

Similarity Evaluation System for Chromatographic Fingerprints of TCMs recommend by the Chinese Pharmacopoeial committee was used for similarity evaluation of chromatographic patterns.

\subsection{Determination of Leonurine, Echinacoside, Acteoside, Catalpol, Aucubin and Polysaccharides}

Simultaneous quantification of leonurine, echinacoside, acteoside, catalpol and aucubin was performed using a described HPLC-TQ-MS with SIR scan mode method [33]. Polysaccharides content were analyzed using a Solarbio Plant soluble sugar Kit (Beijing Solarbio Science \& Technology Co., Ltd., Beijing, China). Numerical data were presented as mean \pm standard deviation (S.D.). Data was analyzed using one-way ANOVA, followed by Student's two-tailed t-test for comparison between wild and transgenic Rehmanniae Radix using the SPSS software package for Windows 11.5 (SPSS, Chicago, IL, USA).

Supplementary Materials: Supplementary materials can be accessed at: http:/ /www.mdpi.com/1420-3049/21/ 9/1134/s1.

Acknowledgments: This research was financially supported by "The National Science Fund for Distinguished Young Scholars (81325023)", “China Postdoctoral Science Foundation Funded Project (2014M551005)” and "State Administration of Traditional Chinese Medicine, Chinese Medicine Scientific Research Projects (201107011)".

Author Contributions: Luqi Huang are the guarantors of this work and, as such, had full access to all the data in the study and take responsibility for the integrity of the data and the accuracy of the data analysis. Luqi Huang and Ye Shen conceived and designed the experiments; Zhongqiu Teng, Ye Shen and Jing Li performed the construction of transgenic plant; Min Chen, Man Li and Hongran Dong evaluated the chemical components of different lines. Zhongqiu Teng and Ye Shen analyzed the data; Zhongping Lin and Min Wang provided valuable methods and suggestions in transformation of the plants; Zhongqiu Teng wrote the paper.

Conflicts of Interest: We acknowledge that no conflicts exist for all authors.

\section{References}

1. Zhang, R.-X.; Li, M.-X.; Jia, Z.-P. Rehmannia glutinosa: Review of botany, chemistry and pharmacology. J. Ethnopharmacol. 2008, 117, 199-214. [CrossRef]

2. Wang, G.; Dong, C.; Shang, Y.; Sun, Y.-A.; Fu, D.; Zhao, J. Characterization of radix rehmanniae processing procedure using FT-IR spectroscopy through nonnegative independent component analysis. Anal. Bioanal. Chem. 2009, 394, 827-833. [CrossRef]

3. Feng, W.; Lv, Y.; Zheng, X.; Zhang, Y.; Cao, Y.; Pei, Y. A new megastigmane from fresh roots of Rehmannia glutinosa. Acta Pharm. Sin. B 2013, 3, 333-336. [CrossRef]

4. Waisundara, V.Y.; Huang, M.; Hsu, A.; Huang, D.; Tan, B.K.-H. Characterization of the anti-diabetic and antioxidant effects of Rehmannia glutinosa in streptozotocin-induced diabetic Wistar rats. Am. J. Chin. Med. 2008, 36, 1083-1104. [CrossRef]

5. Paek, K.; Yu, K.; Park, S.; Sung, N.; Park, C. Internat. Symposium on Medicinal and Aromatic Plants 390. In Micropropagation of Rehmannia glutinosa as Medicinal Plant by Shoot Tip and Root Segment Culture; International Society for Horticultural Science: Kyoto, Japan, 1994; pp. 113-120.

6. Liu, Z.; Lou, Z.; Ding, X.; Li, X.; Qi, Y.; Zhu, Z.; Chai, Y. Global characterization of neutral saccharides in crude and processed Radix Rehmanniae by hydrophilic interaction liquid chromatography tandem electrospray ionization time-of-flight mass spectrometry. Food Chem. 2013, 141, 2833-2840. [CrossRef]

7. Wang, M.; Li, M.; Huang, L.; Chen, Y.; Wu, Z.; Li, G.; Wei, M.; Fang, R. TMV and CMV widely infect cultivated Rehmannia glutinosa Libosch. Zhi Wu Bing Li Xue Bao 2006, 36, 189-192.

8. Liao, J.; Hu, C.; Kao, J.; Deng, T. Identification of Tobacco mosaic virus infecting Rehmannia glutinosa. Plant Pathol. Bull. 2007, 16, 61-69.

9. Beachy, R.N.; Loesch-Fries, S.; Tumer, N.E. Coat protein-mediated resistance against virus infection. Annu. Rev. Phytopathol. 1990, 28, 451-472. [CrossRef] 
10. Abel, P.P.; Nelson, R.S.; De, B.; Hoffmann, N.; Rogers, S.G.; Fraley, R.T.; Beachy, R.N. Delay of disease development in transgenic plants that express the tobacco mosaic virus coat protein gene. Science 1986, 232, 738-743. [CrossRef] [PubMed]

11. Cai, W.-Q.; Fang, R.-X.; Shang, H.-S.; Wang, X.; Zhang, F.-L.; Li, Y.-R.; Zhang, J.-C.; Cheng, X.-Y.; Wang, G.-L.; Mang, K.-Q. Development of CMV-and TMV-resistant chili pepper: Field perfermance and biosafety assessment. Mol. Breed. 2003, 11, 25-35. [CrossRef]

12. Lee, Y.H.; Jung, M.; Shin, S.H.; Lee, J.H.; Choi, S.H.; Her, N.H.; Lee, J.H.; Ryu, K.H.; Paek, K.Y.; Harn, C.H. Transgenic peppers that are highly tolerant to a new CMV pathotype. Plant Cell Rep. 2009, 28, 223-232. [CrossRef]

13. Tougou, M.; Furutani, N.; Yamagishi, N.; Shizukawa, Y.; Takahata, Y.; Hidaka, S. Development of resistant transgenic soybeans with inverted repeat-coat protein genes of soybean dwarf virus. Plant Cell Rep. 2006, 25, 1213-1218. [CrossRef] [PubMed]

14. Tumer, N.E.; O'Connell, K.M.; Nelson, R.S.; Sanders, P.R.; Beachy, R.N.; Fraley, R.T.; Shah, D.M. Expression of alfalfa mosaic virus coat protein gene confers cross-protection in transgenic tobacco and tomato plants. EMBO J. 1987, 6, 1181-1188. [PubMed]

15. Fehér, A.; Skryabin, K.G.; Balázs, E.; Preiszner, J.; Shulga, O.A.; Zakharyev, V.M.; Dudits, D. Expression of PVX coat protein gene under the control of extensin-gene promoter confers virus resistance on transgenic potato plants. Plant Cell Rep. 1992, 11, 48-52. [CrossRef] [PubMed]

16. Lawson, C.; Kaniewski, W.; Haley, L.; Rozman, R.; Newell, C.; Sanders, P.; Tumer, N.E. Engineering resistance to mixed virus infection in a commercial potato cultivar: Resistance to potato virus $\mathrm{X}$ and potato virus $\mathrm{Y}$ in transgenic Russet Burbank. Nat. Biotechnol. 1990, 8, 127-134. [CrossRef]

17. Ting, H.; Meifu, K.; Wei, C.; Yunfeng, W.; Julong, C. Identification of tobacco variety resistance to Tobacco mosaic virus and Cucumber mosaic virus. Plant Prot. 2012. [CrossRef]

18. Peocházková, Z. Interaction of cucumber mosaic virus and potato virus $\mathrm{Y}$ with tobacco mosaic virus. Biol. Plantarum 1970, 12, 297-304. [CrossRef]

19. Syller, J. Facilitative and antagonistic interactions between plant viruses in mixed infections. Mol. Plant Pathol. 2012, 13, 204-216. [CrossRef] [PubMed]

20. Vanderschuren, H.; Stupak, M.; Fütterer, J.; Gruissem, W.; Zhang, P. Engineering resistance to geminiviruses-Review and perspectives. Plant Biotechnol. J. 2007, 5, 207-220. [CrossRef] [PubMed]

21. Halpin, C. Gene stacking in transgenic plants-The challenge for 21st century plant biotechnology. Plant Biotechnol. J. 2005, 3, 141-155. [CrossRef] [PubMed]

22. Van Vu, T.; Choudhury, N.R.; Mukherjee, S.K. Transgenic tomato plants expressing artificial microRNAs for silencing the pre-coat and coat proteins of a begomovirus, Tomato leaf curl New Delhi virus, show tolerance to virus infection. Virus Res. 2013, 172, 35-45.

23. Hackland, A.; Rybicki, E.; Thomson, J. Coat protein-mediated resistance in transgenic plants. Arch. Virol. 1994, 139, 1-22. [CrossRef] [PubMed]

24. Schillberg, S.; Zimmermann, S.; Zhang, M.-Y.; Fischer, R. Antibody-based resistance to plant pathogens. Transgenic Res. 2001, 10, 1-12. [CrossRef] [PubMed]

25. Doreste, V.; Ramos, P.; Enriquez, G.; Rodriguez, R.; Peral, R.; Pujol, M. Transgenic potato plants expressing the potato virus $\mathrm{X}(\mathrm{PVX})$ coat protein gene developed resistance to the viral infection. Phytoparasitica 2002, 30, 177-185. [CrossRef]

26. Woerdenbag, H.J.; Lugt, C.B.; Pras, N. Artemisia annua L.: A source of novel antimalarial drugs. Pharm. Weekbl. 1990, 12, 169-181. [CrossRef]

27. Xie, P.; Chen, S.; Liang, Y.-Z.; Wang, X.; Tian, R.; Upton, R. Chromatographic fingerprint analysis-A rational approach for quality assessment of traditional Chinese herbal medicine. J. Chrom. A 2006, 1112, 171-180. [CrossRef] [PubMed]

28. Wagner, H.; Bauer, R.; Melchart, D.; Xiao, P.-G.; Staudinger, A. Chromatographic Fingerprint Analysis of Herbal Medicines; Springer: Berlin, Gemany, 2011.

29. Novak, W.K.; Haslberger, A.G. Substantial equivalence of antinutrients and inherent plant toxins in genetically modified novel foods. Food Chem. Toxicol. 2000, 38, 473-483. [CrossRef]

30. Kuiper, H.A.; Kleter, G.A.; Noteborn, H.P.; Kok, E.J. Substantial equivalence-An appropriate paradigm for the safety assessment of genetically modified foods? Toxicology 2002, 181, 427-431. [CrossRef] 
31. Parani, M.; Rudrabhatla, S.; Myers, R.; Weirich, H.; Smith, B.; Leaman, D.W.; Goldman, S.L. Microarray analysis of nitric oxide responsive transcripts in Arabidopsis. Plant Biotechnol. J. 2004, 2, 359-366. [CrossRef] [PubMed]

32. Candelier-Harvey, P.; Hull, R. Cucumber mosaic virus genome is encapsidated in alfalfa mosaic virus coat protein expressed in transgenic tobacco plants. Transgenic Res. 1993, 2, 277-285. [CrossRef]

33. Xu, J.; Wu, J.; Zhu, L.Y.; Shen, H.; Xu, J.D.; Jensen, S.R.; Jia, X.B.; Zhang, Q.W.; Li, S.L. Simultaneous determination of iridoid glycosides, phenethylalcohol glycosides and furfural derivatives in Rehmanniae Radix by high performance liquid chromatography coupled with triple-quadrupole mass spectrometry. Food Chem. 2012, 135, 2277-2286. [CrossRef] [PubMed]

Sample Availability: Samples of the compounds are available from the authors.

(C) 2016 by the authors; licensee MDPI, Basel, Switzerland. This article is an open access article distributed under the terms and conditions of the Creative Commons Attribution (CC-BY) license (http://creativecommons.org/licenses/by/4.0/). 